\title{
PENGARUH DISIPLIN, KOMPETENSI DAN KOMPENSASI TERHADAP KINERJA GURU PADA SEKOLAH ISLAM TERPADU PERMATA MADANI
}

\author{
Mukhlis Catio $^{*}$, Sachro Yusuf $\left.{ }^{* *}\right)$, Hafis Aldy ${ }^{* \star *}$ \\ Email : muhlis.imam56@gmail.com
}

\begin{abstract}
ABSTRAK
PENGARUH DISIPLIN, KOMPETENSI DAN KOMPENSASI TERHADAP KINERJA GURU (Analisis Terhadap Kinerja Guru Pada Sekolah Islam Terpadu Permata Madani) Tujuan penelitian ini adalah untuk mengetahui pengaruhdisiplin, kompetensi dan kompensasi terhadap kinerja guru.Pada penelitian ini, variabel independen adalah disiplin (X1), kompetensi (X2) dan kompensasi (X3), sedangkan variabel dependen adalah kinerja guru $(\mathrm{Y})$. penelitian ini dilakukan kepada 82 responden dari 103 populasiyang ada. Hasil pada penelitian menunjukan bahwa disiplin, kompetensi dan kompensasi secara bersamaan berpengaruh signifikan terhadap kinerja guru dengan hasil $F_{\text {hitung }}>F_{\text {tabel }}(65.443>2.72)$ atau dalam persentase sebesar $71.6 \%$, sedangkan sisanya $28.4 \%$ diterangkan oleh variable lain yang tidak diajukan dalam penelitian ini.

Kata kunci : Disiplin, Kompetensi Dan Kompensasi, Kinerja
\end{abstract}

\section{ABSTRACT}

EFFECT OF DISCIPLINE, COMPETENCE AND COMPENSATION ON TEACHER PERFORMANCE (Analysis of Teacher Performance at Madani Integrated Islamic School) The purpose of this study was to determine the effect of discipline, competence and compensation on teacher performance. In this study, the independent variables are discipline (X1), competence (X2) and compensation (X3), while the dependent variable is teacher performance $(Y)$. this research was conducted on 82 respondents from 103 existing populations. The results of the study show that discipline, competence and compensation simultaneously have a significant effect on teacher performance with the results of Fcount> Ftable $(65,443>2.72)$ or in the percentage of $71.6 \%$, while the remaining $28.4 \%$ is explained by other variables not submitted in this study.

Keywords: Discipline, Competence and Compensation, Performance

*) \& **) Dosen Universitas Pamulang

***) Mahasiswa MM Universitas Pamulang

\section{PENDAHULUAN}

\section{A. Latar Belakang Masalah}

Guru sebagai pendidik adalah tokoh utama yang paling banyak bergaul dan berinteraksi terhadap para peserta didik dibandingkan dengan personil lainnya disekolah. Bahkan jika dibandingkan dengan orang tua di rumah. Selain seorang pendidik Guru merupakan seorang yang mampu membimbing, membina, dan melatih para peserta didik.

Guru memiliki tanggung jawab dan peranan dalam merencanakan, melaksanakan, dan mengevaluasi, baik dalam proses pembelajaran, menilai hasil pembelajaran, melakukan bimbingan, dan pelatihan dari sisi intelektualitas (pngetahuan), attitude (perilaku) dan skill (kemampuan) terhadap para peserta didik.

Kualitas peserta didik yang akan menjadi penerus bangsa sangat berpengaruh terhadap kualitas yang dimiliki oleh guru, dan juga mengapa program yang diberikan sekolah dan pemerintah lembaga pendidikan kepada guru untuk peserta didik harus berkualitas dan bersinergi dengan baik. Hal itu untuk memberikan kelancaran dan kebaikan kepada seluruh aspek yang berkaitan dan bersentuhan langsung dalam dunia pendidikan. 
Yayasan Sekolah Islam Terpadu Permata Madani didirikan pada tahun 2014, yang terdiri dari Daycare ,TK, SD, dan SMPyang bergerak dalam bidang pendidikan untuk menciptakan generasi sumber daya manusia yang lebih berkarakter, berkualitas dan berakhlak baik bagi kemajuan masa depan bangsa Indonesia.

Dalam hal ini guru mutlak harus memiliki kualitas yang baik yang meliputi 4 aspek yang ada dalam PERMENDIKNAS no. 16 tahun 2007, tentang standar kualifikasi akademik dan kompetensi guru, di antaranya yaitu: Kompetensi pedagogik, Kompetensi kepribadian, Kompetensi professional dan Kompetensi sosial

Dari variabel disiplin, kompetensi dan kompensasi dapat dilihat bagaimana Kinerja guru. dalam Undang-Undang No. 14 Tahun 2005 Pasal 1 ayat (1) butir 1 tentang Guru dan Dosen dinyatakan bahwa, "Guru adalah pendidik profesional dengan tugas utama mendidik, mengajar, membimbing, mengarahkan, melatih, menilai, dan mengevaluasi peserta didik pada pendidikan anak usia dini jalur pendidikan formal, pendidikan dasar, dan pendidikan menengah".

\section{B. Perumusan Masalah}

Berdasarkan batasan masalah diatas, maka pertanyaan penelitian dapat dirumuskan sebagai berikut:

1. Apakah Disiplin berpengaruh signifikan terhadapKinerja guru?

2. Apakah Kompetensi berpengaruh signifikan terhadap Kinerja guru?

3. Apakah Kompensasi berpengaruh signifikan terhadap Kinerja guru?

4. Apakah Disiplin, Kompetensi dan Kompensasi secara bersamaan berpengaruh signifikan terhadapKinerja guru?

\section{Tujuan Penelitian}

Adapun tujuan dalam penelitian ini adalah sebagai berikut :

1. Untuk mengetahui pengaruh disiplinterhadap kinerja guru.

2. Untuk mengetahui pengaruh kompetensi terhadap kinerja guru.

3. Untuk mengetahui pengaruh kompensasi terhadap kinerja guru.

4. Untuk mengetahui pengaruh Disiplin, kompetensi dan Kompensasi terhadap kinerja guru.

\section{TINJAUAN PUSTAKA}

\section{A. Disiplin}

Menurut (H.A Tabrani Rusyam dan H. Sumina, 2017:3) mendefinisikan disiplin sebagai sikap kesetiaan dan ketaatan guru terhadap peraturan-peraturan pada instansi sekolah untuk tujuan tertentu dengan kesadaran akan tugas dan kewajibannya. Sedangkan Menurut pendapat (Abdus Salam, 2014:194) Disiplin adalah sikap hidup dan perilaku yang mencerminkan tanggung jawab terhadap kehidupan, tanpa paksaan dari luar.Sikap dan perilaku ini dianut berdasarkan keyakinan bahwa hal itu bermanfaat bagi diri sendiri dan masyarakat.

\section{B. Kompetensi}

Menurut UU No. 13/2003 tentang Ketenaga kerjaan pasal 1 ayat 10 : Kompetensi adalah kemampuan kerja setiap individu yang mencakup aspek pengetahuan, keterampilan dan sikap kerja yang sesuai dengan standar yang ditetapkan.Sedangkan 
menurut pendapat Menurut (Wibowo, 2010:324-325) kompetensi merupakan karakteristik individu yang mendasari kinerja atau perilaku ditempat kerja.Kinerja dipekerjaan dipengaruhi oleh; pengetahuan, kemampuan, dan sikap; gaya kerja, kepribadian, kepentingan dan minat, dasar-dasar, nilai sikap, kepercayaan, dan gaya kepemimpinan.

\section{Kompensasi}

Kompensasi sebagai penghasilan guru dalam hal ini telah tertuang pada UU no. 5 Pasal 15 tahun 2005 tentang kewajiban dan hak guru yaitu :

1. Penghasilan di atas kebutuhan hidup minimum sebagaimana meliputi gaji pokok, tunjangan yang melekat pada gaji, serta penghasilan lain berupa tunjangan profesi, tunjangan fungsional, tunjangan khusus, dan maslahat tambahan yang terkait dengan tugasnya sebagai guru yang ditetapkan dengan prinsip penghargaan atas dasar prestasi.

2. Guru yang diangkat oleh satuan pendidikan yang diselenggarakan oleh Pemerintah atau pemerintah daerah diberi gaji sesuai dengan peraturan perundang-undangan.

3. Guru yang diangkat oleh satuan pendidikan yang diselenggarakan oleh masyarakat diberi gaji berdasarkan perjanjian kerja atau kesepakatan kerja bersama.

Sedangkan menurut pendapat Menurut (Hasibuan, 2010:19) Kompensasi adalah semua pendapatan yang berbentuk uang baik langsung maupun tidak langsung sebagai imbalan atas jasa yang diberikan kepada perusahaan.

\section{Kinerja Guru}

Menurut undang-undang republik Indonesia No. 14 tahun 2005 tentag guru dan dosen" guru adalah pendidik profesional dengan tugas utama mendidik, mengajar membimbing mengarahkan melatih, menilai, dan mengevaluasi peserta didik pada pendidikan usia dini, pendidikan dasar dan pendidikan menengah". Dalam undangundang No.14 tahun 2005 dijelaskan bahwa: "guru mempunyai kedudukan sebagai tenaga profesional pada jenjang pendidikan usia dini, pendidikan dasar, dan pendidikan menengah padajalur pendidikan formal yang diagkat sesuai dengan peraturan perundang-undang. (Pasal 2 UU RI No. 14: 2005).

Lebih lanjut disebutkan bahwa : "guru wajib memiliki kualifikasi akademik, kompetensi, sertifikat pendidik, sehat jasmani dan rohani, serta memilik kompetensi untuk mewujudkan tujuan pendidikan nasional" (pasal 7 UU RI No. 14:2005).

Menurut pendapat (E. Mulyasa, 2007:227) ada beberapa faktor yang dapat meningkatkan kinerja guru, yaitu :

1. Dorongan untk bekerja

6. Perhatian

2. Tanggung jawab

3. Minat

4. Penghargaan

5. Peluang untuk berkembang

7. Hubungan interpersonal

8. MGMP dan KKG

9. Kelompok diskusi terbimbing

10. Layanan perpustakaan

\section{METODOLOGI PENELITIAN}

Penelitian ini menggunakan metode analisis regresi berganda berdasarkan penjelasan analisis kuantitatif.Tujuannya adalah untuk menjelaskan aspek-aspek yang sesuai atau relevan dengan fenomena yang diamati dan menjelaskan karakteristik masalah yang ada. 


\section{A. Populasi dan Sampel}

Populasi adalah keseluruhan obyek penelitianyang mempunyai karakteristik tertentu untuk dipelajari dan kemudian ditarik kesimpulan.Populasi dapat berupa orang dan juga benda-benda alam lainnya (Sugiono, 2000-27).Populasi dalam penelitian ini adalah guru Sekolah Islam Terpadu Permata Madanisebanyak 103 orang.

Sampel adlah sebagian dari jumlah dan karakteristik yang dimiliki oleh populasi tersebut (Sugiono, 2000-27) jika populasi besar dan peneliti tidak mungkinmempelajari semua yang ada pada populasikarena keterbatasan dana, tenaga, dan waktu maka penelti dapat menggunakan sampel pada penelitian ini adalah dengan menggunakan rumus Populasi Slovin (Ashari 1996), dengan tingkat ketelitian 5\% diperoleh jumlah sampel 82 orang

\section{B. Metode Pengumpulan Data}

Agar data yang diperlukan dapat dipergunakan secara efektif dan efisien, maka perlu ditetapkan : data apa saja yang dibutuhkan, jenis data apa saja yang perlu ditetapkan, dimana sumber datanya, dan dengan teknik apa saja data dikumpulkan.

\section{Sumber Data}

a. Data Primer

Data primer adalah data yang dikumpulkan oleh peneliti dari responden dan langsung melalui penyebaran angket atau kuesioner di lingkungan Sekolah Islam Terpadu Permata Madani.

b. Data Sekunder

Data sekunder adalah data yang dikumpulkan oleh peneliti yang diperoleh secara langsung melalui buku-buku sumber/kepustakaan

\section{Teknik Penentuan Data}

Teknik penetuan data dalam penelitian ini adalah dengan menggunakan metode analisis regresi dan model statistic deskriptif kuantitatif melalui program SPSS versi 19. Berkut teknik penentuan data yang digunakan dalam penelitian ini :

\section{Statistik Deskriptif}

Menurut (Sugiyono 2013: 147) statistik deskriptif adalah statistik yang digunakan untuk menganalisa data dengan cara menjelaskan gambaran data yang telah terkumpul sebagaimana adanya atau aslinya tanpa bermaksud untuk membuat kesimpulan yang berlaku secara umum, Biasanya dalam statistik deskriptif memberikan gambaran data berdasarkan min, median, modus, standar devisi dan varians.

\section{Uji Kualitas Data}

\section{a. Uji Validitas}

Menurut (Sugiyono, 2013 : 137) Validitas adalah tingkat keandalan dan kesahihan alat ukur yang digunakan. Instrumen dikatakan valid berarti menunjukkan alat ukur yang dipergunakan untuk mendapatkan data itu valid atau dapat digunakan untuk mengukur apa yang seharusnya di ukur.

Adapun rumus yang bisa digunakan untuk uji validitas dengan teknik korelasi product moment, yaitu : 


$$
r_{\text {hitung }}=\frac{n \cdot\left(\sum x y\right)-\left(\sum x\right) \cdot(\Sigma y)}{\sqrt{\left[n\left(\sum x^{2}\right)-(\Sigma x)^{2} \cdot\left(n \cdot \Sigma y^{2}-(\Sigma y)^{2}\right]\right.}}
$$

Jika nilai Pearson Correlation $>0,3$ dinyatakan valid

Jika nilai Pearson Correlation $<0,3$ dinyatakan tidak valid.

\section{b. Uji Reliabilitas}

Uji reliabilitas adalah untuk mengetahui sejauh mana hasil pengukuran tetap konsisten, apabila dilakukan pengukuran dua kali atau lebih terhadap gejala yang sama dengan menggunakan alat pengukur yang sama pula.Teknik pengukuran reliabilitas yang digunakan pada penelitian ini adalah menggunakan teknik Spearman Brown.Menurut (Dr. Riduwan 2013:117-119) Teknik Spearman Brown mempunyai beberapa langkah, yaitu :

Langkah 1: Menghitung Total Skor

Langkah 2: Menghitung Korelasi Product Moment dengan rumus :

$$
\mathrm{r}_{\mathrm{b}}=\frac{n \cdot(\Sigma x y)-(\Sigma x) \cdot(\Sigma y)}{\sqrt{\left\{n\left(\sum x^{2}\right)-(\Sigma x)^{2} \cdot\left(n \cdot \Sigma y^{2}-(\Sigma y)^{2}\right\}\right.}}
$$

Langkah3 :Menghitung reliabilitas seluruh tes dengan rumus Spearman Brown,

$$
\text { yaitu : } r_{11} \frac{2 r_{b}}{1+r_{b}}
$$

Langkah 4 : Mencari $r_{\text {tabel }}$ apabila diketahui signifikansi untuk $\alpha=0,05$ dan $\quad \mathrm{dk}=\mathrm{n}-2$

Langkah 5 : Membuat keputusan membandingkan $r_{11}$ dengan $r_{\text {tabel }}$ Kaidah keputusan : Jika $r_{11}>r_{\text {tabel }}$ berarti Reliabel dan $r_{11}<r_{\text {tabel }}$ berarti tidak Reliabel

\section{Uji Asumsi Klasik}

\section{a. Uji Normalitas}

Uji normalitas dalam penelitian ini dilakukan untuk menguji apakah model regresi, varibel pengganggu atau residual memiliki distribusi normal.

\section{b. Uji Heteroskedastisitas}

Heterokedastisitas merupakan keadaan dimana seluruh residual atau error tidak memiliki varian yang sama untuk seluruh pengamatan atas variabel independen.

\section{c. Uji Multikolinieritas}

Menurut (Sunjoyo dkk., 2013:65), Uji Multikolinieritas adalah untuk melihat ada atau tidaknya korelasi yang tinggi antara variabel-variabel dalam suatu model regresi linier berganda.Gejala multikolinieritas dapat dilihat dari nilai tolerance dan nilai VarianInflaction Factor (VIF). Bila nilai VIF lebih kecil dari nilai toleransinya di atas 0,5 atau 5\% maka dapat disimpulkan bahwa model regresi tersebut tidak terjadi multikolinieritas.

\section{Analisis Regresi}

\section{a. Analisis Regresi Linear Berganda}

Regresi linear berganda adalah pengembangan dari regresi linear sederhana, yaitu sama-sama alat yang dapat digunakan untuk memprediksi permintaan di masa akan datang berdasarkan data masa lalu atau untuk mengetahui pengaruh satu atau lebih variabel bebas (independent) terhadap satu variabel tak bebas (dependent). 
Rumus Regresi Linear Berganda

$Y=a+b_{1} X_{1}+b_{2} X_{2}+b_{3} X_{3} \ldots . .+b_{n} X_{n}$, di mana:

$Y=$ Variabel terikat, a dan $b_{1}$ serta $b_{2}=$ konstanta.

$X_{1}=$ Variabel bebas pertama,

$X_{2}=$ Variabel bebas kedua

$X_{3}=$ Variabel bebas ketiga,

$X_{n}=$ Variabel bebas ke $n$

\section{b. Koefisien Determinasi}

Perhitungan terhadap koefisien determinasi dimaksudkan untuk menganilisis seberapa besar (dinyatakan dalam presentasi) kontribusi variabel bebas terhadap variabel terikat. Berdasarkan perhitungan analisa koefisien rumus yang dipergunakan dalam perhitungan analisa determinasinya :

$$
\mathrm{KD}=\mathrm{r}^{2} \times 100 \%
$$

Keterangan :

$K D=$ Koefisien determinasi

$r \quad=$ Koefisien korelasi

\section{Uji Hipotesis}

\section{a. Uji Signifikan Simultan (Uji Statistik t)}

Uji $F$ atau Pengujian Hipotesis Secara Simultan adalah untuk mengetahui sejauh mana pengaruh secara simultan antara variabel bebas Xterhadap variabel tidak bebas $\mathrm{Y}$. (Menurut Syofian Siregar, 2013:303).

\section{b. Uji Signifikan Simultan (Uji Statistik F)}

Tujuan dilakukan uji signifikansi secara parsial dua variabel bebas (independent) terhadap variabel tak bebas (dependent) adalah untuk mengukur secara terpisah kontribusi yang ditimbulkan dari masing-masing variabel bebas (independent) terhadap variabel tak bebas (dependent).

\section{HASIL DAN PEMBAHASAN}

\section{A. Uji Instrumen Penelitian}

\section{Uji Validitas}

Tabel 4.1 : Hasil Uji Validitas

\begin{tabular}{|c|c|c|c|c|}
\hline Variabel & Indikator & $\mathbf{r}$ Tabel & $\begin{array}{c}\text { Corrected item } \\
\text { correlation sampel }\end{array}$ & Keterangan \\
\hline Disiplin & 1 & 0.217 & $0.500^{* * *}$ & Valid \\
(X1) & 2 & 0.217 & $0.583^{* *}$ & Valid \\
& 3 & 0.217 & $0.611^{* *}$ & Valid \\
& 4 & 0.217 & $0.552^{* *}$ & Valid \\
& 5 & 0.217 & $0.605^{* * *}$ & Valid \\
& 6 & 0.217 & $0.576^{* * *}$ & Valid \\
& 7 & 0.217 & $0.614^{* *}$ & Valid \\
& 8 & 0.217 & $0.625^{* *}$ & Valid \\
& 9 & 0.217 & $0.664^{* *}$ & Valid \\
& 10 & 0.217 & $0.532^{* *}$ & Valid \\
\hline
\end{tabular}


JURNAL ILMIAH ILMU MANAJEMEN

\begin{tabular}{|c|c|c|c|c|}
\hline Variabel & Indikator & r Tabel & $\begin{array}{l}\text { Corrected item } \\
\text { correlation sampel }\end{array}$ & Keterangan \\
\hline Kompetensi (X2) & $\begin{array}{c}1 \\
2 \\
3 \\
4 \\
5 \\
6 \\
7 \\
8 \\
9 \\
10\end{array}$ & $\begin{array}{l}0.217 \\
0.217 \\
0.217 \\
0.217 \\
0.217 \\
0.217 \\
0.217 \\
0.217 \\
0.217 \\
0.217\end{array}$ & $\begin{array}{l}0.724^{*} \\
0.679^{* *} \\
0.666^{*} \\
0.497^{* *} \\
0.496^{* *} \\
0.696^{* *} \\
0.588^{* *} \\
0.659^{* *} \\
0.530^{* *} \\
0.695^{* *}\end{array}$ & $\begin{array}{l}\text { Valid } \\
\text { Valid } \\
\text { Valid } \\
\text { Valid } \\
\text { Valid } \\
\text { Valid } \\
\text { Valid } \\
\text { Valid } \\
\text { Valid } \\
\text { Valid }\end{array}$ \\
\hline $\begin{array}{l}\text { Kompensasi } \\
\text { (X3) }\end{array}$ & $\begin{array}{c}1 \\
2 \\
3 \\
4 \\
5 \\
6 \\
7 \\
8 \\
9 \\
10\end{array}$ & $\begin{array}{l}0.217 \\
0.217 \\
0.217 \\
0.217 \\
0.217 \\
0.217 \\
0.217 \\
0.217 \\
0.217 \\
0.217\end{array}$ & $\begin{array}{l}0.578 \\
0.728^{* *} \\
0.486^{* *} \\
0.604^{* *} \\
0.662^{* *} \\
0.519^{* *} \\
0.555^{* *} \\
0.612^{* *} \\
0.554^{* *} \\
0.726^{* *}\end{array}$ & $\begin{array}{l}\text { Valid } \\
\text { Valid } \\
\text { Valid } \\
\text { Valid } \\
\text { Valid } \\
\text { Valid } \\
\text { Valid } \\
\text { Valid } \\
\text { Valid } \\
\text { Valid }\end{array}$ \\
\hline $\begin{array}{c}\text { Kinerja } \\
(Y)\end{array}$ & $\begin{array}{c}1 \\
2 \\
3 \\
4 \\
5 \\
6 \\
7 \\
8 \\
9 \\
10\end{array}$ & $\begin{array}{l}0.217 \\
0.217 \\
0.217 \\
0.217 \\
0.217 \\
0.217 \\
0.217 \\
0.217 \\
0.217 \\
0.217\end{array}$ & $\begin{array}{l}0.811^{*} \\
0.709^{* *} \\
0.568^{* *} \\
0.486^{* *} \\
0.670^{* *} \\
0.7888^{* *} \\
0.716^{* *} \\
0.741^{* *} \\
0.697^{* *} \\
0.675^{* *}\end{array}$ & $\begin{array}{l}\text { Valid } \\
\text { Valid } \\
\text { Valid } \\
\text { Valid } \\
\text { Valid } \\
\text { Valid } \\
\text { Valid } \\
\text { Valid } \\
\text { Valid } \\
\text { Valid }\end{array}$ \\
\hline
\end{tabular}

Sumber: Data primer yang diolah SPSS v.19

Berdasarkan data di atas, kesimpulan dari uji validitas ini dari 40 pernyataan, keseluruhan pernyataan dari tiap-tiap variabel dinyatakan valid. Hal ini dibuktikan dengan nilai corrected item-total correlation lebih besar dari t tabel $(0,217)$. Dapat disimpulkan bahwa butir-butir pernyataan dari masing-masing variabel dapat digunakan untuk mengukur dalam pengujian selanjutnya.

\section{Uji Reliabilitas}

Tabel 4.2 : Uji Reliabilitas Data

\begin{tabular}{|c|c|c|}
\hline Variabel & Cronbach's Alpha & $\begin{array}{c}\text { Kategori Interval } \\
\text { Reliabilitas }\end{array}$ \\
\hline Disiplin (X1) & 0.785 & Reliabel \\
\hline Kompetensi (X2) & 0,799 & Reliabel \\
\hline Kompensasi (X3) & 0,804 & Reliabel \\
\hline Kinerja (Y) & 0,877 & Sangat Reliabel \\
\hline
\end{tabular}

Sumber: Data yang diolah SPSS v.19

Berdasarkan tabel di atas, dapat disimpulkan bahwa hasil uji reliabilitas dengan program SPSS v.19 didapatkan untuk variabel disiplin (X1) nilai Cronbach's Alpha 0,785 adalah sangat reliable, sedangkan untuk variabel kompetensi (X2) nilai Cronbach's Alpha 
0,799 adalah sangat reliable, untuk variabel kompensasi (X3) nilai Cronbach's Alpha 0,804 adalah sangat reliable dan variabel kinerja $(\mathrm{Y})$ nilai Cronbach's Alpha 0,877 adalah sangat reliabel.Jadi keseluruhan pernyataan pada penelitian ini memiliki tingkat kehandalan yang baik dan dapat digunakan dalam analisis pada penelitian ini.

\section{B. Uji Asumsi Klasik}

1. Uji Normalitas

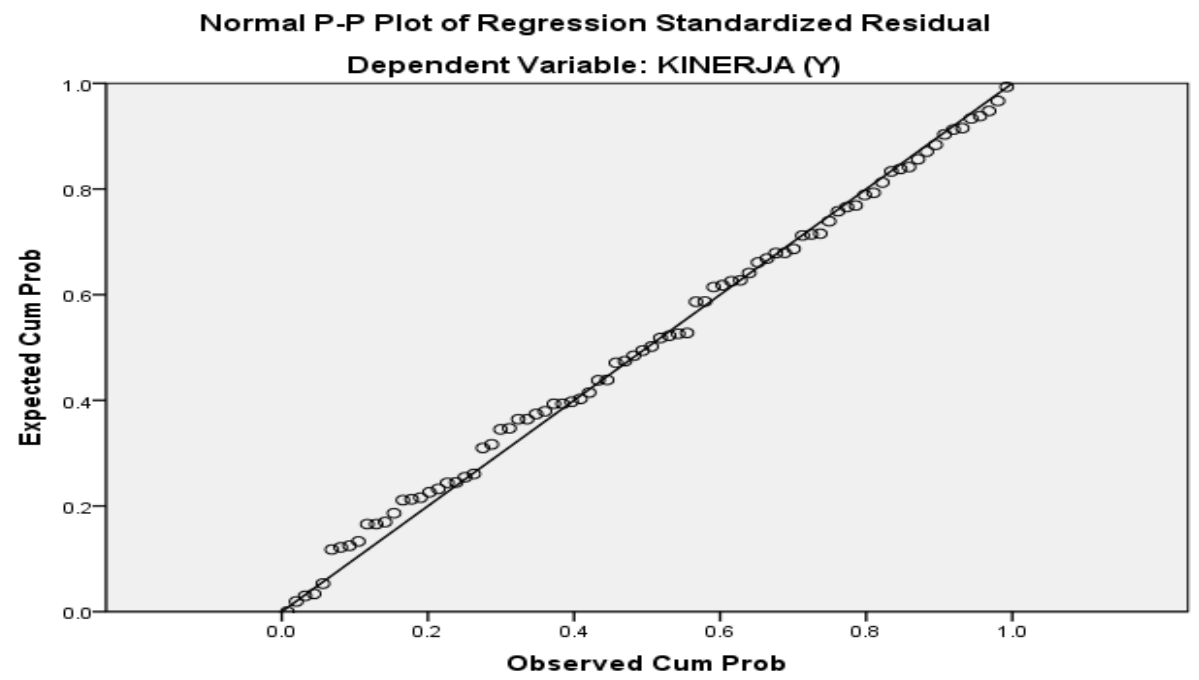

Berdasarkan gambar grafik diatas menunjukan bahwa terdapat hubungan linear.Dan dapat dilihat ilustrasi diatas menunjukan bahwa titik - titik berada disekitar garis diagonal, sehingga dapat dikatakan bahwa seluruh data terdistribusi secara normal.

\section{Uji Heteroskedastisitas}

Heterokedastisitas merupakan keadaan dimana seluruh residual atau error tidak memiliki varian yang sama untuk seluruh pengamatan atas variabel independen.

\section{Uji Multikolinearitas}

Tabel 4.3 : Hasil Uji Multikolinearitas

\begin{tabular}{|l|r|r|r|r|r|}
\hline \multirow{2}{*}{ Model } & \multicolumn{2}{|c|}{$\begin{array}{c}\text { Unstandardized } \\
\text { Coefficients }\end{array}$} & $\begin{array}{c}\text { Standardized } \\
\text { Coefficients }\end{array}$ & \multicolumn{2}{|c|}{$\begin{array}{c}\text { Collinearity } \\
\text { Statistics }\end{array}$} \\
\cline { 2 - 6 } & \multicolumn{1}{|c|}{$\mathrm{B}$} & Std. Error & \multicolumn{1}{c|}{ Beta } & Tolerance & \multicolumn{1}{c|}{ VIF } \\
\hline (Constant) & 2.208 & 3.772 & & & \\
DISIPLIN (X1) & .034 & .109 & .025 & .561 & 1.781 \\
KOMPETENSI (X2) & .645 & .104 & .637 & .347 & 2.885 \\
KOMPENSASI (X3) & .270 & .132 & .226 & .298 & 3.354 \\
\hline
\end{tabular}

Sumber : Data diolah SPSS V.19

Berdasarkan tabel coefficients di atas, nilai Variance Inflation Factor (VIF) dari masing-masing variabel independent tidak memiliki nilai yang lebih dari 10 , sehingga dapat disimpulkan bahwa model regresi dalam penelitian ini tidak mengandung multikolinieritas. 


\section{Analisis Regresi}

\section{Analisis Regresi Linear Berganda}

Tabel 4.4 : Hasil Regresi Linear

Coefficients $^{a}$

\begin{tabular}{|l|r|r|r|r|r|}
\hline \multirow{2}{*}{ Model } & \multicolumn{2}{|c|}{$\begin{array}{c}\text { Unstandardized } \\
\text { Coefficients }\end{array}$} & $\begin{array}{c}\text { Standardized } \\
\text { Coefficients }\end{array}$ & & \\
\cline { 2 - 5 } & \multicolumn{1}{|c|}{$\mathrm{B}$} & Std. Error & \multicolumn{1}{c|}{ Beta } & \multicolumn{1}{c|}{$\mathrm{t}$} & Sig. \\
\hline (Constant) & 2.208 & 3.772 & & .585 & .560 \\
DISIPLIN (X1) & .034 & .109 & .025 & .313 & .755 \\
KOMPETENSI (X2) & .645 & .104 & .637 & 6.212 & .000 \\
KOMPENSASI (X3) & .270 & .132 & .226 & 2.045 & .044 \\
\hline
\end{tabular}

a. Koefesien regresi Disiplinb ${ }_{1}=0.034$ dapat diartikan bahwa jika nilai Disiplinmeningkat sebesar satu maka nilai Kinerja juga akan meningkat sebesar 0.034 .

b. Koefesien regresi Kompetensib ${ }_{2}=0.645$ dapat diartikan bahwa jika nilai Kompetensi meningkat sebesar satu maka nilai Kinerja juga akan meningkat sebesar 0.645.

c. Koefesien regresiKompensasi $b_{2}=0.270$ dapat diartikan bahwa jika nilai Kompensasi meningkat sebesar satu maka nilai Kinerja juga akan meningkat sebesar 0.270.

d. Koefesien regresi Kompensasi $b_{2}=0.270$ dapat diartikan bahwa jika nilai Kompensasi meningkat sebesar satu maka nilai Kinerja juga akan meningkat sebesar 0.270 .

\section{Koefisien Determinasi $\mathbf{R}^{2}$ Kompensasi Terhadap Kinerja Guru ( $\mathrm{X}_{3}$ dan $\mathrm{Y}$ ) Tabel 4.5 : Hasil Uji Koefisien Determinasi $R^{2} X_{1}, X_{2}, X_{3}$ Dan $Y$} Model Summary ${ }^{\mathrm{b}}$

\begin{tabular}{|l|c|c|c|c|}
\hline Model & $\mathrm{R}$ & $\mathrm{R}$ Square & Adjusted R Square & Std. Error of the Estimate \\
\hline 1 & $.846^{\mathrm{a}}$ & .716 & .705 & 3.386 \\
\hline
\end{tabular}

a. Predictors: (Constant), KOMPENSASI (X3), DISIPLIN (X1), KOMPETENSI (X2)

b. Dependent Variable: KINERJA (Y)

Sumber: Peneliti, Output SPSS V.19

Dari tabel di atas didapat nilai Adjusted $R$ Square sebesar 0.716 yang menunjukkan bahwa variabel $Y$ (Kinerja) dipengaruhi oleh variabel $X_{1}$ (Dsiplin), variabel $\mathrm{X}_{2}$ (Kompetensi) dan variabel $\mathrm{X}_{3}$ (Kompensasi) sebesar $71.6 \%$ dan sisanya sebesar $28.4 \%$ dipengaruhi oleh faktor-faktor lain yang tidak diteliti.

\section{Uji Hipotesis}

\section{Uji Parsial (Uji t)}

Kriteria taraf signifikan sebesar 5\% (0.05) dan membandingkan t-hitung dengan ttabel dengan kriteria sebagai berikut:

a. Jika t-hitung $<\mathrm{t}$-tabel berarti $\mathrm{H}_{0}$ diterima dan $\mathrm{H}_{1}$ ditolak

b. Jika t-hitung $>\mathrm{t}$-tabel berarti $\mathrm{H}_{0}$ ditolak dan $\mathrm{H}_{1}$ diterima

Adapun ketentuan t-tabel diperoleh dengan cara jumlah responden $n=82-4=78$ dilihat dari distribusi nilai t tabel (terlampir) maka nilai t tabel 1,664.Berikut ini adalah hasil pengujian yang disajikan dalam tabel berikut : 
Tabel 4.6 : Hasil Uji Statistik t

Coefficients $^{a}$

\begin{tabular}{|l|r|r|r|r|r|}
\hline \multirow{2}{*}{ Model } & \multicolumn{2}{|c|}{$\begin{array}{c}\text { Unstandardized } \\
\text { Coefficients }\end{array}$} & $\begin{array}{c}\text { Standardized } \\
\text { Coefficients }\end{array}$ & & \\
\cline { 2 - 5 } & \multicolumn{1}{|c|}{$\mathrm{B}$} & Std. Error & \multicolumn{1}{c|}{ Beta } & \multicolumn{1}{c|}{$\mathrm{t}$} & Sig. \\
\hline (Constant) & 2.208 & 3.772 & & .585 & .560 \\
DISIPLIN (X1) & .034 & .109 & .025 & .313 & .755 \\
KOMPETENSI (X2) & .645 & .104 & .637 & 6.212 & .000 \\
KOMPENSASI (X3) & .270 & .132 & .226 & 2.045 & .044 \\
\hline
\end{tabular}

Dependent Variable: Kinerja Guru $(\mathrm{Y})$

a. Koefesien regresi Disiplinb ${ }_{1}=0.034$ dapat diartikan bahwa jika nilai Disiplinmeningkat sebesar satu maka nilai Kinerja juga akan meningkat sebesar 0.034 .

b. Koefesien regresi Kompetensib ${ }_{2}=0.645$ dapat diartikan bahwa jika nilai Kompetensi meningkat sebesar satu maka nilai Kinerja juga akan meningkat sebesar 0.645.

c. Koefesien regresiKompensasi $b_{2}=0.270$ dapat diartikan bahwa jika nilai Kompensasi meningkat sebesar satu maka nilai Kinerja juga akan meningkat sebesar 0.270.

\section{KESIMPULAN DAN SARAN}

\section{A. Kesimpulan}

Berdasarkan hasil penelitian, maka dapat disimpulkan sebagai berikut :

1. Disiplin berpengaruh signifikan terhadap kinerja guru dengan hasil $t_{\text {hitung }}$ lebih besar $t_{\text {tabel }}(5.798>1.664)$ atau dalam persentasesebesar 29,6\%, sedangkan sisanya sebesar $70,4 \%$ diterangkan oleh variabel lain.

2. Kompetensi berpengaruh signifikan terhadap kinerja guru dengan hasil $t_{\text {hitung }}$ lebih besar $t_{\text {tabel }}(13.506>1.664)$ atau dalam persentase sebesar $69,5 \%$, sedangkan sisanya sebesar $30,5 \%$ diterangkan oleh variabel lain.

3. Kompensasi berpengaruh signifikan terhadap kinerja guru dengan hasil $t_{\text {hitung }}$ lebih besar $t_{\text {tabel }}(10.318>1.664)$ atau dalam persentasesebesar $57,1 \%$, sedangkan sisanya sebesar $42,9 \%$ diterangkan oleh variabel lain.

4. Disiplin, kompetensi dan kompensasi secara bersamaan berpengaruh signifikan terhadap kinerja guru dengan hasil $F_{\text {hitung }}>F_{\text {tabel, }}(65.443>2.72)$ atau dalam persentase sebesar $71,6 \%$, sedangkan sisanya $28,4 \%$ dierangkan oleh variable lain yang tidak diajukan dalam penelitian ini seperti motivasi, pelatihan, dan lainnya.

\section{B. SARAN}

Berdasarkan dari hasil penelitian dan analisa data yang terdapat dalam penelitian ini, penulis memberikan masukan dan saran sebagai berikut :

1. Berkaitan dengan disiplin, setiap guru wajib mengikuti SOP yang ada pada sekolah, hal ini agar dapat memberikan hal positif terhadap anak didik terutama dalam hal perilaku dan juga bagi guru dari segi kompensasi, baik langsung maupun tidak langsung.

2. Berkaitan dengan kompetensi, setiap guru mutlakharus menguasai 4 hal dasar kompetensi, yaitu :

a. Kompetensi Pedagogic 
b. Kompetensi pribadi

c. Kompetensi Professional

d. Kompetensi Sosial

Hal agar dapat dijadikan tolak ukur bagi pihak sekolah dalam penilaian kinerja guru dalam hal proses, pelaksanaan dan evaluasi anak didik.

\section{DAFTAR PUSTAKA}

\section{A. UNDANG - UNDANG \& PERATURAN TERKAIT}

PERMENDIKNAS No. 44/U/2002 Tahun 2002 Tentang Komite Sekolah. No. 16 Tahun 2007. Tentang Standar Kualifikasi Akademik Dan Kompetensi Guru.

Peraturan Menteri Negara Pendayagunaan Aparatur Negara Dan Reformasi Birokrasi No. 16 Tahun 2009, Tentang PK Guru.

Peraturan Pemerintah RI No. 19 Tahun 2005, Tentang Standar Nasional Pendidikanpasal28 ayat 3.

Sekretariat Negara RI, Permendiknas Nomor 41 Tahun 2007 tentang Standar Proses untuk Satuan Pendidikan Dasar dan Menengah, Departemen Pendidikan Nasional.

\section{B. BUKU}

E.Mulyasa. 2007,Standar Kompetensi dan Sertifikasi Guru, Remaja Rosdakarya, Bandung.

Tabrani Rusyam, Sumina. 2017, Menjadi Guru Berdisiplin. Cet. 1 Tegal : CV. Nabil Sukses Mandiri.

Riduwan, DR., 2013, Metode dan Teknik Menyusun Tesis, Alfabeta, Bandung

John R. Schermerhorn Jr. 2011, Management. John Wiley, New York. Hasibuan, Malayu S.P, 2012. Manajemen Sumber Daya Manusia. Bumi Aksara, Jakarta Moeheriono. 2014, Pengukuran Kinerja Berbasis Kompetensi - Competency Based Human Resources Management, Edisi Revisi Cetakan ke 2. Rajawali Pers, Jakarta.

Suyanto, Asep Jihad.2013, Menjadi Guru Profesional Strategi Meningkatkan Kualifikasi dan Kualitas Guru di Era Global. Penerbit Erlangga, Jakarta. 